\title{
Immigration Enforcement and Fairness to Would-Be Immigrants
}

\author{
Hrishikesh Joshi \\ Draft; forthcoming in The Handbook of Philosophy and Public Policy, David Boonin ed. \\ Palgrave MacMillan. Please cite the published version.
}

\begin{abstract}
This chapter argues that governments have a duty to take reasonably effective and humane steps to minimize the occurrence of unauthorized migration and stay. While the effects of unauthorized migration on a country's citizens and institutions have been vigorously debated, the literature has largely ignored duties of fairness to would-be immigrants. It is argued here that failing to take reasonable steps to prevent unauthorized migration and stay is deeply unfair to would-be immigrants who are not in a position to bypass visa regulations. Importantly, the argument here is orthogonal to the debate as to how much and what kinds of immigration ought to be allowed.
\end{abstract}

\section{Rules and Exceptions}

Imagine the following scenario. A new drug is invented to cure a certain type of chronic pain. From the initial testing it appears that the drug is highly successful and has few mild side effects. However, given existing Food and Drug Administration (FDA) regulations, the drug must go through further tests before it is released to the market. This process will take several years. For many people with this type of chronic disease, the prospect of taking the new drug, risks and all, is much better than living with constant pain for years. In addition, there are many more people with this type of chronic pain (several thousands) than there are spots for the next phase of testing (one hundred), given the numbers defined by the regulations. So, not everybody who wants to enter the testing phase is going to get a spot. How to make the cutoff? A lottery system is devised whereby one hundred subjects are selected out of a pool of thousands.

Now suppose that Martha has this chronic disease, but has not won the lottery. However she happens to know Bob, who works at the front desk where the clinical trial is held. Martha asks Bob if he can get her into the trial somehow. As it turns out, Bob knows that Bill, who is in charge of the trial processes in the hospital, doesn't really have a system in place to make sure that people who are let in by the front desk are really the ones who are part of the trials. So Bob tells Martha to just show up at the relevant times, and he will let her through.

For the first few weeks, things go smoothly, and Martha comes in regularly for treatment. But midway through the clinical trial, one of the nurses realizes that Martha is in the trial 
outside of the rules of the lottery. As this news breaks, what would be the reaction?

People would be rightly outraged. They will be outraged on behalf of the thousands who wanted the drug but couldn't get it because they didn't win the lottery. Clearly, it is not fair to such individuals that Martha, who also lost in the lottery, gets to receive the drug. Martha is being made an exception of - she is not made to play by the rules that the rest are made to play by.

I want to focus discussion particularly on the behavior of Bill, the trial administrator. He commits a serious wrong by being negligent in his duty to make sure that the people who are in the trial are those who won the lottery. He should have checked and made sure that the hundred winners are actually the ones who receive the treatment. Alternatively, he could have set up an automated system to ensure that the admission rules of the trials are followed. By not taking such precautions, he is being unfair to all the other people who desperately wanted the drug but did not win the lottery.

Maybe Bill thinks there shouldn't be such a trial process before the drugs are released into the market. Or maybe he thinks the trial should admit two hundred people instead of one hundred. However, this is irrelevant because he is bound to treat people unfairly if he strays from the official procedure. The lottery has been completed already and so he can't go back and make it the case that there are two hundred randomized winners instead of one hundred. Neither is he in a position to administer the drug to anybody who wants it he will have to announce this publicly and will get fired if he so blatantly ignores FDA regulations.

Bill's negligence invites a serious justified complaint on behalf of the people with the chronic pain who did not win the lottery. The complaint is serious because of how important the drug can be to their lives. It would be less serious if this were a raffle for trinkets. And the complaint sticks because the difference between all these people and Martha - namely that she has a connection with the front desk staffer - is not of the requisite kind. Things shouldn't be set up so that people with this kind of fortuitous connection are able to get into medical trials for very important drugs.

\section{The Case of Immigration Enforcement}

The case described above is analogous in key respects to immigration enforcement in many areas of the modern world. Given that countries vary drastically in terms of the economic and social opportunities they offer to their residents, there are many people who want to migrate, particularly to the developed world. However, the developed world imposes legal limits on the number of immigrants it accepts. These restrictions are enforced quite uniformly when it comes to air travel and in many cases of sea travel. In general, it is not possible for someone to board a plane headed to a different country without the proper documentation. However, in some cases where countries share land borders, migrants are able to cross into the neighboring country's territory in significant numbers and reside there, even when they are not legally authorized to do so. In many cases it's plausible that the receiving country's government could do more to reduce the occurrence of such migration without prohibitive cost. In such cases, the government is acting wrongly just as Bill is in the scenario above. 
Consider for example the case of the U.S. According to the latest IMF estimates, the U.S. has a GDP per capita of $\$ 59,610$, one of the very highest in the world. Compare this to Bangladesh's GDP per capita of $\$ 4,210$, adjusted for purchasing power parity. India's GDP is at $\$ 7,150$ PPP per capita. ${ }^{1}$ GDP isn't everything of course, but it is a very good proxy for human development (as measured by the Human Development Index, for example) and social progress. ${ }^{2}$ Higher GDP correlates strongly with greater literacy, better medical care, higher life expectancy, lower government corruption, better roads, etc. The differences in GDP value are thus a reasonable indicator of how much better the American standard of living is. Bangladesh and India have a combined population of around 1.5 billion people - many of whom, given the differential standard of living, would like to immigrate to the U.S.

Imagine you are a textile worker in Bangladesh. You work for more than 12 hours a day, 6-7 days a week, for a few cents per hour. By Western standards, the conditions you live in are best described as squalid and slum-like. Perhaps your children will be able to escape this poverty, but sending them to college seems out of the question. Would you want to move to the U.S. with your family if given a chance? Many people in this situation would. In the U.S. you can make more in an hour, working for a minimum wage job, than what you make in a Bangladeshi sweatshop in a day, and this is a huge boost even controlling for differential purchasing power. Your children will get access to much better education, and with the generous financial aid programs in some universities, may well go to college one day. The infrastructure, sanitation, social liberties, etc. are also much better in the U.S. Indeed, your quality of life is likely to drastically improve as a result of your move. The fact that people in such circumstances would want to move to the U.S. is further bolstered by the observation that many South Asian workers move to Gulf States like Qatar or the UAE despite terrible worker protections and no hope for ever attaining any political rights. ${ }^{3}$

So why don't Bangladeshi sweatshop workers move to the U.S. en masse? The reason is that the U.S., along with every other country, imposes limits on immigration. Not everybody who wants to move to the U.S. or Germany or Australia can legally do so. The U.S. for instance, grants about one million permanent residencies per year. The quota goes mostly towards family reunification, which rules out foreigners who do not have such ties to the U.S. Natives of a select group of countries can apply for the Diversity Lottery, but the odds of getting through are quite low, as there are only 50,000 spots per year. There are refugee programs, but they would not apply to the typical resident of Bangladesh or India. Lastly, a small number of highly skilled workers can gain residency through employment, but that doesn't apply to the typical resident either. ${ }^{4}$

\footnotetext{
${ }^{1}$ See International Monetary Fund (2017).

${ }^{2}$ See Social Progress Initiative (2016) and United Nations Development Programme (2015).

${ }^{3}$ See for example, Vora (2013).

${ }^{4}$ For details of current U.S. legal permanent residence policy, see USCIS (2017).
} 
Being in compliance with immigration law while staying in the U.S. on an indefinite basis requires official permanent residence (or a "green card"). But entering the U.S. without a green card or worker visa while intending to stay indefinitely is also very difficult for the typical resident of Bangladesh or India to do. This is because such a resident cannot board a plane headed to the country without a visa. ${ }^{5}$ Thus the way to enter the U.S. and subsequently remain illegally would involve at least getting a tourist visa. And even a tourist visa, for the typical resident of Bangladesh, is hard to get. Among the things you have to prove to get such a visa is that you're not going to abandon residence in your home country. This stipulation is, of course, there by design. However, if you're a poor sweatshop worker, it's rational for you to abandon Bangladeshi residence (i.e. plan not to return) once you reach the U.S. The American Consulate, knowing this, will likely deny your application. So even if you wanted to move to the U.S. illegally from Bangladesh, it would be quite hard for you to do so.

On the other hand, the U.S. has a land border with Mexico that is not nearly as secure as it could be. As a result, millions of Central American natives have been, over the years, successful at entering and staying in the U.S. outside of the legal immigration channels. ${ }^{6}$ Furthermore, the U.S. could take steps to better ensure that people employed within its territory have the authorization to do so. Orrenius and Zavodny (2016) have recently marshaled evidence suggesting that this could be achieved with automated employment verification systems (sometimes called "E-verify"). Such a system would also reduce the number of visa overstays.

The analogy, then, is the following. The U.S. government is like the negligent boss, Bill, who doesn't ensure lottery winners are in fact the people who participate in the trial. Just as in this case there are many more people who want the drug (which will dramatically improve their lives) than there are spots in the trial, there are many more people who want to move to the U.S. than there are permanent residencies available. The individuals who are able to enter and stay within the country outside of the immigration rules, owing to lax physical border security and/or lack of an employment tracking system are analogous to Martha, who gets into the trial outside of the rules. Therefore, just as Bill's actions are deeply unfair to those who desperately want the drug but did not win the lottery, the U.S. government's actions are deeply unfair to the millions of people who desperately want to move to the U.S. but are unable to do so owing to visa regulations. For Bill, the additional checking measures will involve some costs, but these are not prohibitive. Therefore, they do not form a good excuse for his unfair actions. Likewise, the U.S. government will incur some additional costs in implementing whatever policy is

\footnotetext{
${ }^{5}$ The U.S. has a visa waiver program for a select group of countries, but they are all developed. See U.S. Department of State (2017) for a full list. The reason these countries are all developed is that the chance that a citizen of one of them would use a tourist visa to enter the U.S. and then choose to abandon residence is much smaller than for developing countries.

${ }^{6}$ Analysis done by Migration Policy Institute (2014) shows that as of 2014, 71\% of undocumented immigrants in the U.S. were from Mexico and Central America. Given the massive overrepresentation relative to population, it's reasonable to infer that the shared land border makes it easier to migrate to the U.S. without the relevant authorization. See also PEW Research (2014) for a further breakdown of countries of origin.
} 
the most effective in reducing unauthorized migration (perhaps E-verify or more robust physical border fencing) but these are not prohibitive and thus do not form a good excuse for the government's unfair negligence. ${ }^{7}$

For the purposes of this chapter, I will not aim to specify exactly what the threshold for acceptable costs is. However, one important feature of this threshold is that it will vary with the moral importance of the issue at hand. In the medical trial, something very important - namely the relief of chronic pain - hangs in the balance. Hence the threshold of costs that hospital administrators ought to be willing to put up with is much higher than in the case of enforcing the rules of a raffle for trinkets. In the case of immigration, obviously something very important hangs in the balance - namely the massive improvement in life prospects that a potential immigrant from a poor country can experience if allowed to move to the U.S. Hence the threshold for acceptable costs in setting up E-Verify or physical barrier systems will be non-trivial.

Secondly, some of these costs may be borne by a wide range of people - but this in itself is not a decisive reason not to take the relevant steps. In the case of the medical trial, the security systems that are set up may impose a variety of costs on people - added waiting times, unsightliness, and so on. Perhaps the hospital would look nicer if it weren't for these security systems. But, plausibly, this isn't a good enough reason not to ensure that the trial rules are followed. Likewise, an E-Verify system will add some transaction costs to employment confirmation procedures. Physical barriers are unsightly to some. These considerations, however, are not sufficient to override the demands of fairness especially when people's life prospects hang in the balance in a serious way.

\section{The Scope of the Argument}

The argument I want to make is a limited one. I claim that the U.S. government behaves unfairly when it fails to put in place certain immigration enforcement mechanisms. I wish to remain neutral on whether the actions of undocumented migrants themselves (analogous to Martha) are morally justified. Many authors argue that undocumented migrants do not commit a moral wrong by entering and remaining illegally within a country. Rocha (2013) argues that unauthorized immigrants do not have obligations to obey certain immigration laws. Hidalgo (2015) has further argued that migrants may resist unjust immigration restrictions - this too, is orthogonal to my argument. I also want to remain neutral on the question of whether individuals or businesses are justified in employing immigrants without the relevant authorization. Furthermore, I do not wish to argue, contra Hidalgo (2016), that individuals have a duty to aid immigration officials in

\footnotetext{
${ }^{7}$ There is some dispute as to how much completed border fencing on the southern border would cost. The U.S. Government Accountability Office estimates that the construction of such fencing would cost around $\$ 3.9$ million per mile - see Government Accountability Office (2009). Part of the 1,933-mile border is already fenced, but even supposing the whole border had to be redone, the cost of doing so would be $\$ 7.54$ billion, given the G.A.O. estimate. This one-time cost would comprise $0.2 \%$ of the total yearly U.S. Federal Budget of \$3.76 trillion - see White House Office of Management and Budget (2015). A leaked memo from the Department of Homeland Security, reported in Ainsley (2017), put the estimated cost much higher, at $\$ 21.6$ billion. This is still less than $1 \%$ of the government's yearly budget.
} 
enforcement. Lastly, I make no general claims about what rights undocumented migrants ought to have while present in a country's territory. Carens (2008) has argued that "irregular migrants," as he calls them, ought to have rights of due process, public schooling up to a certain age, the ability to seek medical help without fear of deportation, and so on. I can grant this, for the sake of argument. All that is relevant here in this regard is that undocumented migrants do not have the legal right to work or live in the country.

Another important point here is that not all sorts of enforcement will be justified by my argument. In the medical trial analogy, it would be wrong for Bill to set up a mechanism that instantly vaporizes any unauthorized entrant into the trial. However, he is justified in using an automated tracking system. He is also plausibly justified in using security guards instructed to humanely escort Martha out of the facility if she runs past the scanners. Similarly, as Mendoza (2015) and Sager (2016) have pointed out, there are moral constraints on what states can do to enforce their immigration laws - some types of enforcement will be impermissible. However, there are forms of enforcement that won't fall under this problematic category - for instance, an automated employment verification system or a guarded physical barrier at the border. If any such measures would be effective in reducing unauthorized entry and stay, and they won't be prohibitively costly, the state acts unfairly by failing to put them in place.

In addition, whether or not Bill acts unfairly in the medical case depends on whether he took reasonable precautions to prevent Martha's entry into the trial. His moral failing is one of negligence. Thus if he had taken reasonable precautions, and Martha was able to get in despite the precautions, Bill would not be to blame. Suppose Bill sets up a reasonably secure automated system to track patients, but Martha hires an expert hacker to break into the system and add her name to the list. In such a case, Bill is off the hook.

Similarly, I don't want to claim that a country like the U.S. acts unfairly towards the Bangladeshi textile worker so long as there is some unauthorized entry and/or stay. Rather, whether or not the U.S. acts unfairly depends on whether it takes reasonable steps to prevent unauthorized entry and stay. Of course despite these efforts, there will be some instances of unauthorized entry and/or stay, but these will not be morally problematic in the way that current patterns of unauthorized entry and stay are.

One challenging moral issue that the case of Martha raises is whether she should be allowed to continue within the trial despite having entered outside of the rules. Plausibly, the answer will depend on the specifics of the case. What will be the effect on Martha if the treatment is discontinued half way? Will allowing Martha to complete the treatment have adverse effects on the rest of the trial process? How expensive is the drug, and is there enough to go around to complete the trial? Importantly, even if it turns out that all things considered Martha ought to be allowed to stay and complete the trial, it is still the case that the fact that she was able to enter the trial is deeply unfair to the thousands who wanted in. Allowing her to continue in the trial (even if it turns out to be the overall correct thing to do) is also unfair to them - she's receiving a good that she should not have received, and that they were barred from receiving, according to pre-determined rules. Moreover, it is still true that Bill ought to have prevented her entry by taking reasonable precautions, even if, given that the trial is half completed, Martha should be allowed to complete the treatment. 
Analogously, some authors have argued that depending upon the context, unauthorized migrants ought to be granted legal residency within the host country. Carens (2013) argues that irregular migrants' claim to stay strengthens over time as they set up roots in the country. Williams (2009) contends in a similar vein that unauthorized workers and their families should be granted legal residence if they have contributed to the U.S. economy for a sufficiently long period of time. Furthermore, the claim to stay presumably is stronger for children brought by unauthorized migrants at a young age. These points do not conflict with my core argument. Even if these authors are right, the U.S. government acted unfairly in allowing such migration to take place when it could have taken reasonable steps to reduce its occurrence. Most importantly, from a forwardlooking perspective, the government ought to take reasonable steps where possible to reduce instances of unauthorized migration and stay. Failure to do so both in the past and the present is unfair to the millions of individuals who would want to live in the U.S. were they allowed to do so.

Now, I have set up the drug case so that the drug being tested can cure chronic pain, and thus dramatically improve the lives of those suffering from that pain. The fact that Martha is not one of the lottery winners, along with the fact that the rules were set in advance by the FDA, grounds an obligation on Bill's behalf to take steps to ensure that she does not participate in the trial. Nonetheless, this obligation can be overridden by exigencies. Suppose that doctors demonstrate, after the FDA rules were set up, that Martha will certainly die without the drug. In such a case, Bill might be justified in taking her into the trial outside of the rules, especially if time is running out for Martha and the rules take a while to change. Importantly, however, he should also make this option available to all the others who will die if they don't receive the drug - an exception should not be made on behalf of Martha.

Similarly, there's an important distinction to be made between economic migrants and refugees (though, in practice the distinction often gets blurred). Refugees are individuals fleeing imminent mortal danger or targeted persecution. A refugee situation may arise rapidly so that there isn't enough time to change immigration law in order to accommodate them. In such a situation, it's plausible that the executive should have discretion to admit such individuals. However, the executive ought to extend the accommodation to all the individuals who fit the bill - they shouldn't make exceptions for some. In cases where it's not possible, for economic or security reasons, say, to accept all refugees into a particular country, the executive should aim to coordinate with other countries to ensure that everybody is accommodated. Importantly, however, in cases where the number of refugees exceeds the number of spots available even after coordination, some set of rules will need to be adopted to determine which individuals get in. In such a case, there's an obligation to follow those rules that are set in advance, for the same reason as is evident in the original case. 


\section{Are Open Borders Arguments Relevant to the Enforcement Issue?}

There is a live and open debate as to whether immigration restrictions are justified in the first place. Many authors have argued for open borders (usually with a proviso included for certain kinds of violent criminals). This list includes Huemer (2010), Carens (1987), Freiman and Hidalgo (2016), among many others. On the contrary, Wellman (2008) argues that states have the right to freedom of association, which grounds their right to exclude foreigners. Miller (2016) and Macedo $(2007 ; 2011)$ have argued that immigration restrictions can be justified insofar as they are necessary to promote certain social goals (for example: cultural preservation, maintaining social trust, or prioritizing co-citizens in poverty). Yet others, such as Pevnick (2009), resist the conclusion that goals such as promoting social trust and social justice require robust immigration restriction policies.

What if the defenders of open borders are ultimately right? Does the U.S. government, along with other countries in similar positions, still have obligations to take reasonable steps to enforce the immigration rules on the books - i.e. to minimize the occurrence of unauthorized entry and stay? It might be tempting to think: if borders should be open anyways, then it's not the case that the U.S. government should take further steps towards immigration enforcement.

Let's go back to the drug testing case. As it happens, it's not obvious that people shouldn't be able to take whatever drugs they want before regulatory testing is complete. For example, Flanigan $(2012 ; 2017)$ has argued that patients should have the right to "pharmaceutical freedom." The requirement that drugs pass a testing phase before people are legally able to buy them is a regulation we should get rid of, according to Flanigan.

Suppose Flanigan is right. Does that mean Bill acts as he ought to? Plausibly, no. He still ought to ensure that the people in the trial are those who won the lottery, as per the rules set in advance. Failure to do so is deeply unfair to all the people who want the drug but did not win the lottery. Of course, if Flanigan is right, then the rules ought to be changed. We should lobby the FDA to change its rules and we should ask our representatives to enshrine pharmaceutical freedom in law. What this doesn't mean, however, is that Bill is right to be negligent in enforcing the rules. That's simply not his prerogative, and moreover, he cannot do it in a way that's justifiable to the thousands of patients who seek the drug.

The mere fact that a law ought to be changed does not mean that authorities should have discretion in arbitrarily failing to enforce that law. Consider another example. There are good arguments to be had that marijuana possession ought to be legalized. ${ }^{8}$ Even if these arguments are right, it doesn't follow that authorities are justified in arbitrarily applying possession laws. It would be deeply unfair, for example, if police enforced marijuana possession restrictions in Neighborhood A but not Neighborhood B, even if it wouldn't be difficult to apply them in the latter. The residents of Neighborhood A would have a serious and justified moral complaint against the authorities if this were the norm.

${ }^{8}$ See for instance Huemer (2004). 
Likewise, suppose the open borders arguments are ultimately successful. The right thing to do then would be to seek to change immigration law so as to reflect this moral reality. Or suppose, more weakly, that the U.S. and other similar countries ought to be more generous in their immigration laws than they currently are. Thus perhaps instead of granting one million green cards per year, the U.S. ought to grant five million. If this is true, then the just thing to do is to democratically arrive at a set of laws that permits five million legal permanent residents per year, and then fairly enforce permissions to enter in accordance with the new law. The de facto policy, in which the U.S. fails to take reasonably effective steps to reduce unauthorized immigration, is deeply unfair to millions of would-be immigrants.

Some readers who are convinced by open borders arguments might see my claim that governments have a duty to take reasonable steps towards uniform enforcement as calling for a kind of leveling down. ${ }^{9}$ Preventing the unauthorized entry and stay for a migrant from Guatemala doesn't make the Bangladeshi textile worker any better off. So how can we owe it to the Bangladeshi textile worker to prevent such entry and stay?

This objection fails, however, because we have obligations to treat people fairly, and fulfilling these obligations does not always boil down to improving their welfare. I may have a fairness-based obligation toward you to $\phi$ even if you are not made better off by my $\phi$-ing. This is brought out in the case of Martha and the medical trial. Moreover, it is a commonplace feature of the moral domain. Suppose that at the beginning of the semester, I announce that there will be a fixed penalty per day that papers are turned in late. Looking to avoid these penalties, you make sure over the course of the semester to turn in papers on time. At several points, you would have liked extra time to work on the papers, but you make sacrifices to turn things in according to schedule. Another student chooses to turn in several papers a day or two late, without any fitting excuse. At the end of the semester, may I choose not to penalize him for his lateness? My penalizing him will not benefit you. In fact, you will never find out his grade anyway, so my failure to penalize him won't even cause you psychological distress. Yet, it seems overwhelmingly plausible that I owe it to you to penalize him. I would be treating you unfairly if I didn't.

\section{Conclusion}

A country's government acts unfairly in cases where more people want to move to the country than there are legally assigned spots, if it fails to take reasonably effective, humane, and not prohibitively costly steps to prevent unauthorized entry and stay. Such a government's actions are unfair to the would-be immigrants who are prevented from moving to the country by enforced immigration laws.

This point has been largely missed in the immigration literature because normally we don't incorporate would-be immigrants into the moral calculus within this context. The case of Martha and the FDA is meant to bring this into focus: when a strongly desired

\footnotetext{
${ }^{9}$ This terminology was popularized by Parfit (1997), in which it is used in framing an objection to a certain type of egalitarianism.
} 
good is being allocated, it is deeply unfair to make some people play by the rules but not others.

The argument of this chapter is not beside the point even if the open-borders theorists were to win the immigration debate. If they're right, then we should try to remove immigration restrictions from the books. Keeping immigration restrictions in place but turning a relative blind eye to those in a position to avoid them is unfair to the millions of people who want to move to the developed world but cannot due to oceans and visa requirements.

ACKNOWLEDGEMENTS: I would like to thank Jonathan Anomaly, Daniel Jacobson, and Eduardo Martinez for extremely useful comments on an earlier draft. Many thanks also to David Boonin for helpful feedback during the editing process. 


\section{References}

Ainsley, Julia Edwards. 2017. "Exclusive - Trump Border 'Wall' to Cost \$21.6 Billion, Take 3.5 Years to Build: Internal Report." February. http://www.reuters.com/article/ususa-trump-immigration-wall-exclusive/exclusive-trump-border-wall-to-cost-21-6-billiontake-3-5-years-to-build-internal-report-idUSKBN15O2ZN.

Carens, Joseph. 1987. "Aliens and Citizens: The Case for Open Borders." The Review of Politics 49 (2): 251-273.

(2): $163-186$.

. 2013. The Ethics of Immigration. Oxford University Press.

Flanigan, Jessica. 2012. “Three Arguments Against Prescription Requirements.” Journal of Medical Ethics.

- 2017. Pharmaceutical Freedom: Why Patients Have a Right to Self Medicate. Oxford University Press.

Freiman, Christopher, and Javier Hidalgo. 2016. "Liberalism or Immigration Restrictions, but Not Both." Journal of Ethics and Social Philosophy 10 (2).

Government Accountability Office. 2009. "Secure Border Initiative Fence Construction Costs." GAO-09-244R. Washington, DC: Government Accountability Office.

Hidalgo, Javier. 2015. "Resistance to Unjust Immigration Restrictions." The Journal of Political Philosophy 23 (4): 450-470.

- 2016. "The Duty to Disobey Immigration Law." Moral Philosophy and Politics 3 (2): 165-186.

Huemer, Michael. 2004. “America’s Unjust Drug War.” In The New Prohibition, edited by Bill Masters. Accurate Press.

461.

International Monetary Fund. 2017. "GDP Based on PPP Per Capita." http://www.imf.org/external/datamapper/PPPPC@WEO/THA.

Macedo, Stephen. 2007. "The Moral Dilemma of U.S. Immigration Policy: Open Borders Versus Social Justice?” In Debating Immigration, edited by Carol M. Swain. Cambridge University Press.

_. 2011. "When and Why Should Liberal Democracies Restrict Immigration?" In Citizenship, Borders, and Human Needs, edited by R. Smith, 301-23. University of Pennsylvania Press.

Mendoza, José Jorge. 2015. "Enforcement Matters: Reframing the Philosophical Debate over Immigration.” The Journal of Speculative Philosophy 29 (1): 73-90. 
Migration Policy Institute. 2014. "Profile of the Unauthorized Population: United States." https://www.migrationpolicy.org/data/unauthorized-immigrant-population/state/US.

Miller, David. 2016. Strangers in Our Midst: The Political Philosophy of Immigration. Harvard University Press.

Orrenius, Pia M., and Madeline Zavodny. 2016. "Do State Work Eligibility Verification Laws Reduce Unauthorized Immigration?" IZA Journal of Migration 5 (5).

Parfit, Derek. 1997. "Equality and Priority." Ratio 10 (3): 202-221.

Pevnick, Ryan. 2009. "Social Trust and the Ethics of Immigration Policy." The Journal of Political Philosophy 17 (2): 146-167.

PEW Research. 2014. "Chapter 2: Birthplaces of U.S. Unauthorized Immigrants." http://www.pewhispanic.org/2014/11/18/chapter-2-birthplaces-of-u-s-unauthorizedimmigrants/.

Rocha, James. 2013. "Unauthorized but Permitted: Limits on the Legal Obligations of Unauthorized Immigrants." Philosophy in the Contemporary World 20 (1).

Sager, Alex. 2016. "Immigration Enforcement and Domination: An Indirect Argument for Much More Open Borders." Political Research Quarterly.

Social Progress Initiative. 2016. "Are GDP and the Social Progress Index Connected?" http://www.socialprogressimperative.org/are-gdp-and-the-social-progress-indexconnected/.

U.S. Department of State. 2017. https://travel.state.gov/content/travel/en/usvisas/tourism-visit/visa-waiver-program.html.

United Nations Development Programme. 2015. "Human Development Data (19902015)." http://hdr.undp.org/en/data.

USCIS. 2017. "Green Card.” https://www.uscis.gov/greencard.

Vora, Neha. 2013. Impossible Citizens: Dubai's Indian Diaspora. Duke University Press.

Wellman, Christopher Heath. 2008. "Immigration and Freedom of Association." Ethics 119: 109-141.

White House Office of Management and Budget. 2015. "The Budget." https://www.whitehouse.gov/omb/budget/Overview.

Williams, Reginald. 2009. "Illegal Immigration: A Case for Residency." Public Affairs Quarterly 23 (4): 309-323. 